\title{
Jurnal Ilmiah Kesehatan
}

Vol. 20 No. 3 Tahun 2021

DOI : 10.33221/jikes.v20i3.1445

\section{Efektivitas Program Penyuluhan Penggunaan Alat Pelindung Diri (APD) pada Petani Bawang Merah saat Pemberian Pestisida di Desa Tegalglagah}

\author{
${ }^{1 *}$ Sahuri, ${ }^{2}$ Sarah Arasy \\ ${ }^{1,2}$ Program Studi Keselamatan dan Kesehatan Kerja, Fakultas Kesehatan Masyarakat Universitas Binawan
}

\begin{abstract}
ABSTRAK Masalah kesehatan yang sering dijumpai pada petani bawang merah adalah penggunaan pestisida yang sangat berisiko sehingga dapat berdampak buruk terutama bagi kesehatan dan keselamatan kerja petani bawang merah. Salah satu cara yang dapat dilakukan untuk mengurangi risiko paparan pestisida adalah penggunaan Alat Pelindung Diri (APD). Tujuan Penelitian ini untuk mengetahui pengetahuan dan sikap petani bawang merah di Desa Tegalglagah dalam penggunaan APD saat melakukan pemberian pestisida. Subjek penelitian ini adalah 30 petani bawang merah yang bertugas menyemprotkan pestisida ke sawah Desa Tegalglagah, Kec. Bulakamba, Kab. Brebes, Jawa Tengah. Teknik analisis data dalam penelitian ini menggunakan analisis data deskriptif kuantitatif dimana desain penelitian kuantitatifnya menggunakan Quasi Eksperimen. Instrumen pengukuran yang digunakan berupa kuesioner berjumlah 30 pertanyaan. Pengukuran dilakukan sebanyak 2 (dua) kali dengan pengukuran pertama pendahuluan sebelum perlakuan dilakukan (Pre test) dan pengukuran kedua dilakukan setelah adanya intervensi (Post test). Intervensi dengan memberi informasi atau penyuluhan tentang pentingnya penggunaan APD saat pemberian pestisida. Berdasarkan hasil analisis bivariat yang telah dilakukan menggunakan uji wilcoxon didapatkan skor signifikansi 0,000 $(<0,05)$. Artinya terdapat perbedaan signifikan antara skor Pre Test dan Post Test. Maka dapat dikatakan bahwa penyuluhan yang dilakukan sudah efektif.
\end{abstract}

Kata Kunci

ABSTRACT

Key Words
Pengetahuan, Sikap, Alat Pelindung Diri (APD), Pestisida.

Health problems that are often found in shallot farmers are the use of pesticides that are very risky so that it can have a negative impact especially for the health and safety of the work of red onion farmers. One way that can be done to reduce the risk of pesticide exposure is the use of self-protective equipment (APD). The purpose of this study was to determine the knowledge and attitude of the red onion farmer in Tegalglagah Village in the use of APD while giving pesticides. The subjects of this study were 30 red onion farmers in charge of spraying pesticides into the rice fields of Tegalglagah Village, Kec. Bulakamba, Kab. Brebes, Central Java. The data analysis technique in this study uses quantitative descriptive data analysis where the design of quantitative research uses quasi experiments. The measurement instrument used in the form of a questionnaire amounted to 30 questions. Measurement was carried out as many as 2 (two) times with the first measurement of preliminary prior before treatment (pre test) and the second measurement was carried out after the intervention (Post Test). Intervention by providing information or counseling about the importance of using APD during pesticides. Based on the results of the bivariate analysis that had been carried out using the Wilcoxon test was obtained a significance score of $0,000(<0.05)$. This means that there is a significant difference between Pre Test and Post Test scores. It can be said that counseling is effective.

Knowledge, Attitude, Personal Protective Equipment (APD), Pesticides.
Recieved
Revised
Accepted : 15 Juli 2021 : 23 Juli 2021 : 7 November 2021
Correspondence $^{\star}$ : Sahuri, Program Studi Keselamatan dan Kesehatan Kerja, Fakultas Kesehatan Masyarakat Universitas Binawan, email : sahuri@binawan.ac.id 


\section{PENDAHULUAN}

Masalah kesehatan yang sering dijumpai pada petani bawang adalah penggunaan pestisida yang sangat berisiko sehingga berbahaya bagi kesehatan dan keselamatan kerja petani. Pengguna pestisida dengan jenis highly toxic kebanyakan dipergunakan di negara berkembang termasuk Indonesia.

Kasus keracunan pestisida di negara berkembang sangat tinggi. Bahkan di negara maju, salah satu penyebabnya karena ketidaktahuannya dalam menggunakan Alat Pelindung Diri (APD) dan tidak pernah mendapatkan informasi atau pengetahuan tentang pentingnya alat pelindung diri dalam menyemprot pestisida. ${ }^{1}$ Untuk mengurangi faktor risiko terpapar pestisida salah satu cara yang dapat dilakukan adalah dengan menggunakan alat pelindung diri. $^{2}$

Secara global WHO memperkirakan keracunan pestisida menyebabkan 300.000 kematian per tahun dan kebanyakan terjadi di negara-negara berpenghasilan rendah dan menengah. ${ }^{3}$ Menurut WHO, keracunan pestisida baik yang disengaja maupun tidak disengaja merupakan masalah yang serius pada komunitas pertanian di Negara miskin dan berkembang yang diperkirakan sekitar 250.000 kematian terjadi karena keracunan pestisida setiap tahunnya. ${ }^{4}$ Alat pelindung diri merupakan salah satu cara yang dapat digunakan tenaga kerja untuk melindungi sebagian atau seluruh tubuhnya dari adanya potensi bahaya atau kecelakaan kerja.

Berdasarkan sebuah penelitian lain didapatkan bahwa $50 \%$ petani tidak memakai baju lengan panjang, $50 \%$ petani tidak memakai masker, $65 \%$ petani tidak memakai sarung tangan, $75 \%$ petani tidak memakai sepatu boot, 75\% petani tidak pakai kacamata, 50\% petani tidak memakai celana panjang. ${ }^{5}$

Pengusaha sektor informal pada umumnya kurang memperhatikan kaidah keamanan dan kesehatan kerja (Icohis,2009). ${ }^{6}$ Salah satu bentuk kerja sektor informal adalah pertanian, pekerjaan bertani akan selalu berhubungan dengan beberapa jenis bahan kimia lainnya, termasuk pestisida semprot yang digunakan petani merupakan suatu keharusan dan sarana untuk membunuh hama-hama tanaman. ${ }^{6}$ Sepatu kerja atau sepatu boot sangat diperlukan pada penyemprotan pestisida. ${ }^{7}$ Dapat terbuat dari kulit, karet sintetik atau plastik. ${ }^{7}$ Ketika menggunakan sepatu boot ujung celana tidak boleh dimasukkan ke dalam sepatu, karena cairan pestisida dapat masuk ke dalam sepatu. ${ }^{7}$

Kata pestisida berasal dari kata pest $=$ hama (jazad pengganggu) dan $c i d a=$ pembunuh, jadi artinya pembunuh hama (jazad pengganggu) yang bertujuan meracuni hama, tetapi kurang atau tidak meracuni tanaman maupun hewan (Triharso, 2004:244). ${ }^{8}$ Pestisida yang banyak digunakan dipasaran termasuk yang sering digunakan oleh petani bawang merah yakni jenis pestisida sintetis. Kemungkinan terjadinya keracunan semakin besar apabila petani sering terpapar pestisida terutama dalam jumlah yang tidak sedikit.

Pengawasan penggunaan pestisida yang dilakukan saat ini belum sesuai dengan Peraturan Menteri Pertanian RI Nomor 107/Permentan/SR.140/9/2014 tentang pengawasan pestisida yang menekankan bahwa pengawasan juga harus dilakukan terhadap keselamatan dan kesehatan kerja.

Terdapat beberapa faktor yang dapat mempengaruhi ketidaktepatan penggunaan pestisida. Salah satunya adalah pengetahuan sikap atau perilaku manusia dalam penggunaan pestisida dan penggunaan APD.

Provinsi Jawa Tengah terdiri dari beberapa kabupaten salah satunya Pemuda Tani Makmur Tegalglagah Kecamatan Bulakamba, Brebes yang rata-rata penduduknya bekerja sebgai petani. Masih terdapat banyak petani yang tidak mengetahui tentang pentingnya penggunaan alat pelindung diri dalam melakukan pemberian pestisida serta sikap yang kurang baik dalam pemberian pestisida.

\section{METODE}

Metode penelitian ini menggunakan eskperimen semu dengan teknik pengambilan purposive sampling dan untuk memperoleh hasil penelitian menggunakan Uji Wilcoxon. Dengan demikian dapat diketahui lebih akurat, karena dapat membandingkan dengan diadakan sebelum diberi perlakuan. ${ }^{9}$ Kriteria sampel dalam penelitian ini adalah Petani Bawang Merah 
Penyemprot Pestisida Desa Tegalglagah Kecamatan Bulakamba Kabupaten Brebes yang berjumlah 30 orang yang terkumpul dalam kelompok Pemuda Tani Bawang Merah Desa Tegalglagah Bulakamba Brebes, Jawa Tengah. Waktu pelaksanaan penelitian ini dimulai dari bulan Maret s/d November 2021.

Variabel independen pada penelitian ini adalah Pengetahuan dan Sikap. Sedangkan variabel dependen adalah penggunaan APD terhadap pemberian pestisida. Dalam pengolahan data, penelitian ini menggunakan analisis kuantitatif untuk mengolah dan mengelompokkan data dimana analisis tersebut dapat memberikan hasil yang dapat diinterpretasikan. Selain itu dilakukan pula analisis data dengan menggunakan analisis univariat dan bivariat.

\section{HASIL}

Berdasarkan data yang diperoleh pada tabel 1 . didapatkan bahwa dari total 30 responden, usia $\geq$ 30 tahun memiliki frekuensi tertinggi sebanyak 26 responden dengan persentase $86,7 \%$ dan usia $<30$ tahun memiliki frekuensi terendah yaitu sebanyak 4 responden dengan persentase 13,3\%. Pada tingkat pendidikan didapatkan bahwa dari total 30 responden, tingkat pendidikan rendah (SD \& SMP) memiliki frekuensi tertinggi sebanyak 24 responden dengan persentase $80 \%$ dan tingkat pendidikan tinggi (SMA) memiliki frekuensi terendah yaitu sebanyak 6 responden dengan persentase 20\%. Sedangkan pada masa kerja terdapat 9 responden dengan persentase sebesar 30\% yang memiliki masa kerja <10 tahun. Sisanya, terdapat sebanyak 21 responden dengan presentase sebesar $70 \%$ yang memiliki masa kerja $\geq 10$ tahun.

\section{Tabel 1. Distribusi Frekuensi Responden} Berdasarkan Karakteristik Responden

\begin{tabular}{lcc}
\hline Karakteristik Responden & $\mathrm{n}=30$ & $100 \%$ \\
\hline Usia & $\mathrm{F}$ & $\%$ \\
\hline $\begin{array}{l}\geq 30 \text { tahun } \\
<30 \text { tahun }\end{array}$ & 26 & $86,7 \%$ \\
\hline Tingkat Pendidikan & 4 & $13,3 \%$ \\
\hline $\begin{array}{l}\text { Pendidikan Rendah } \\
\text { (SD\&SMP) }\end{array}$ & $\mathrm{F}$ & $\%$ \\
$\begin{array}{l}\text { Pendidikan Tinggi } \\
\text { (SMA) }\end{array}$ & 6 & $24 \%$ \\
\hline Masa Kerja & $\mathrm{F}$ & $\%$ \\
\hline$\geq 10$ tahun & 21 & $70 \%$ \\
$<10$ tahun & 9 & $30 \%$ \\
\hline
\end{tabular}

Berdasarkan analisis deskriptif di atas diketahui pada hasil pre test, semua responden yaitu 30 orang (100\%) memiliki tingkat pengetahuan cukup terhadap penggunaan APD. Kemudian setelah dilakukan penyuluhan dan dilakukan post test, hasilnya semua responden yaitu 30 orang (100\%) memiliki tingkat pengetahuan yang baik mengenai penggunaan APD.

Tabel 2. Gambaran Perbedaan Tingkat Pengetahuan Petani Bawang Merah Sebelum dan Sesudah diberi Penyuluhan Materi APD

\begin{tabular}{lcccc}
\hline Pengetahuan & $\begin{array}{c}\text { Pre } \\
\text { Test }\end{array}$ & Persentase & $\begin{array}{c}\text { Post } \\
\text { Test }\end{array}$ & Persentase \\
\hline Baik & 0 & - & 30 & $100 \%$ \\
Cukup & 30 & $100 \%$ & 0 & - \\
Kurang & 0 & - & 0 & - \\
\hline Total & 30 & $100 \%$ & 30 & $100 \%$ \\
\hline
\end{tabular}

Berdasarkan hasil analisis deskriptif di atas hasil pre test menunjukkan ada 6 responden (20\%) memiliki

Tabel 4. Hasil Uji Wilcoxon Perbedaan Perbedaan Pengetahuan dan Sikap Sebelum dan Sesudah Intervensi

\begin{tabular}{|c|c|c|c|c|c|c|c|}
\hline Intervensi & & $\mathrm{N}$ & Mean & $\begin{array}{l}\text { Std. } \\
\text { Dev }\end{array}$ & Min-Maks & $\mathrm{Z}$ & nilai $\mathrm{p}$ \\
\hline \multicolumn{8}{|l|}{ Pengetahuan } \\
\hline \multirow[t]{2}{*}{ Penyuluhan } & Pre Test & 30 & 9.53 & 1.042 & $8-11$ & $-4.805^{\mathrm{b}}$ & 0,000 \\
\hline & Post Test & 30 & 14.80 & .925 & $13-16$ & & \\
\hline \multicolumn{8}{|l|}{ Sikap } \\
\hline \multirow[t]{2}{*}{ Penyuluhan } & Pre Test & 30 & 12.73 & 3.600 & $9-26$ & $-4.729^{b}$ & 0,000 \\
\hline & Post Test & 30 & 22.40 & 2.372 & $17-27$ & & \\
\hline
\end{tabular}


sikap penggunaan APD baik, sedangkan 24 responden (80\%) memiliki sikap penggunaan APD yang kurang baik. Setelah dilakukan penyuluhan dan post test didapatkan hasil semua responden yaitu 30 orang (100\%) memiliki sikap penggunaan APD yang baik.

Tabel 3. Gambaran Perbedaan Sikap Petani Bawang Merah terhadap Penggunaan APD saat Pemberian Pestisida Sebelum dan Sesudah diberi Penyuluhan Materi APD

\begin{tabular}{ccccc}
\hline Sikap & $\begin{array}{c}\text { Pre } \\
\text { Test }\end{array}$ & Persentase & $\begin{array}{c}\text { Post } \\
\text { Test }\end{array}$ & Persentase \\
\hline Baik & 6 & $20 \%$ & 30 & $100 \%$ \\
$\begin{array}{c}\text { Kurang } \\
\text { Baik }\end{array}$ & 24 & $80 \%$ & 0 & - \\
\hline Total & 30 & $100 \%$ & 30 & $100 \%$ \\
\hline
\end{tabular}

Berdasarkan hasil analisis pengetahuan, diketahui skor rata-rata (mean) pre test adalah 9,53 sedangkan skor rata-rata post test adalah 14,80. Artinya terdapat peningkatan pengetahuan setelah dilakukan penyuluhan. Selanjutnya dilakukan uji wilcoxon pengetahuan dan didapatkan skor signifikansi 0,000 $(<0,05)$ artinya terdapat perbedaan signifikan antara skor pre test dan post test.

Tabel 5. Hasil Analisis Statistk Uji Wilcoxon (SPSS) terhadap Efektivitas Program Penyuluhan Penggunaan Alat Pelindung Diri (APD) Pada Petani Bawang Merah Saat Pemberian Pestisida.

\begin{tabular}{lr}
\hline & $\begin{array}{c}\text { Post Test - } \\
\text { PreTest }\end{array}$ \\
\hline $\mathrm{Z}$ & $-6.771^{\mathrm{b}}$ \\
nilai p (2-tailed) & 0,000 \\
\hline Wilcoxon Signed Ranks Test
\end{tabular}

Berdasarkan hasil uji wilcoxon didapatkan skor signifikansi 0,000 $(\leq 0,05)$. Artinya terdapat perbedaan signifikan antara skor Pre Test dan Post Test.

\section{PEMBAHASAN}

Berdasarkan hasil penelitian pada tabel 2, bahwa sebagian besar responden menunjukkan pengetahuan cukup sebanyak 30 orang (100\%) sebelum diberi penyuluhan mengenai APD. Responden yang memiliki pengetahuan cukup sebagian besar berada dalam usia 20-30 tahun. Hal ini dimungkinkan karena adanya pengaruh orang lain yang dianggap penting dalam kehidupan sehari-hari seperti keluarga dan teman kerja sehingga akan berpengaruh terhadap pengetahuan mereka. Jors dkk. (2006) dan Ngowi dkk. (2007) menyatakan bahwa di Bolivia dan negaranegara Afrika kampanye yang masif dari perusahaan pestisida sangat berpengaruh terhadap pengetahuan dan sikap petani sehingga cenderung menggunakan pestisida yang intensif. ${ }^{10}$

Selain itu, pada tingkat pendidikan Petani Bawang Merah yang mayoritas hanya berjenjang SD memungkinkan kurangnya informasi seputar cara bekerja yang aman sulit didapat selama menjadi petani. Peran pendidikan tentu merupakan upaya untuk memberikan pengetahuan yang baik secara dasar mengenai keselamatan dan kesehatan kerja sehingga terjadi perubahan dalam meningkatanya pengetahuan yang positif. Banyaknya informasi akan pengetahuan yang diperoleh seseorang dapat meningkatkan perubahan sikap menjadi lebih baik. Tingkat pengetahuan merupakan salah satu faktor internal yang berpengaruh pada praktik penggunaan APD.

Setelah diberikan intervensi berupa penyuluhan terkait APD saat pemberian pestisida, 30 responden memiliki tingkat pengetahuan yang tentunya meningkat sebanyak (100\%). Terlihat dari tabel 2, bahwa terjadi peningkatan pengetahuan seluruh responden yang berjumlah 30 dengan pengetahuan cukup (0\%) sebelum dilakukan penyuluhan kemudian berubah menjadi (100\%) setelah dilakukannya penyuluhan.

Tolak ukur pendidikan menjadikan bahwa semakin tinggi pendidikan seseorang maka kualitas sumber daya manusianya semakin tinggi. Pada penelitian ini, tingkat pendidikan mayoritas responden berpendidikan rendah (SD) sehingga pada kenyataannya praktik dalam penggunaan APD tidak sesuai sebagaimana mestinya. Hal ini dikarenakan responden merasa kurang nyaman dan akan menggangu pekerjaan mereka sebagai penyemprot 
pestisida apabila harus menggunakan APD secara lengkap.

Berdasarkan hasil penelitian pada tabel 3, didapati bahwa terdapat 6 responden yang memiliki sikap baik dengan persentase sebesar (20\%) dan 24 responden dengan persentase sebesar (80\%) yang memiliki sikap kurang baik saat Pre Test. Menurut Allport dalam Azwar (2013) sikap adalah semacam kesiapan untuk bereaksi terhadap suatu objek dengan cara-cara tertentu. Agar sikap dapat terwujud menjadi sebuah tindakan, diperlukan faktor pendukung atau kondisi yang memungkinkan antara fasilitas dan dukungan.

Sikap merupakan suatu penilaian seseorang terhadap stimulus yang diberikan dan dimana selanjutnya setelah stimulus maka sesorang akan bertindak dalam bersikap.

Sesuai dengan teori Ilham Noviandri (2013). Bahwa perilaku seseorang dapat deipengaruhi oleh pengamatan (perception) merupakan tahap pertama dimana seseorang akan mengamati suatu bahaya tersebut, maka seseorang tersebut tidak akan menampilkan adanya perilaku kerja yang aman. ${ }^{11}$

AlatPelindung Diriyangterkadangkelengkapannya masih kurang membuat responden memakai peralatan seadanya dan cenderung tidak mendukung program keselamatan dan kesehatan kerja yang ada. Menurut responden, bahwa APD berupa sepatu boots, kacamata dipikir akan mengganggu pekerjaan dan membuat rasa kurang nyaman. Kebiasaan petani dalam pemakaian APD sangat dipengaruhi oleh beberapa faktor. Diantaranya adalah kondisi lapangan atau area kerja persawahan, dan ketersediaan APD yang tidak lengkap.

Bilapun APD tersebut tersedia, responden merasa hal tersebut tidak praktis dan akan sangat tidak nyaman untuk digunakan sampai pekerjaan selesai. Pada umumnya, praktik dalam penggunaan APD yang paling banyak dipakai dandirasa nyaman oleh responden saat memberikan pestisida yaitu: penutup kepala, masker, pakaian dan celana panjang. Sedangkan sepatu boots dan kacamata merupakan APD yang paling banyak tidak dipakai oleh responden.

Pada umumnya petani beranggapan bahwa pestisida tidak berbahaya bagi manusia atau kalaupun menimbulkan bahaya tidak akan berakibat fatal terhadap kesehatan. Bahkan beberapa petani merasa dirinya kebal atau menganggap ringan terhadap bahaya pestisida sehingga merasa tidak begitu perlu memperhatikan tata cara penanganan dan aplikasi pestisida yang baik dan benar (Sularti, 2012). ${ }^{12}$

Untuk menghindari dampak buruk yang ditimbulkan pestisida perlu adanya upaya preventif terhadap para petani terutama yang bekerja dengan paparan pestisida. Salah satu upaya tersebut adalah dengan menggunakan APD. Penggunaan APD dapat mencegah timbulnya penyakit akibat kerja. Maka dari itu diperlukan peran dan usaha yang harus dilakukan baik oleh Pengusaha dalam menyediakan APD dengan tepat dan lengkap serta oleh Petani Bawang Merah yang berhadapan langsung dengan pestisida agar terhindar dari bahaya keracunan pestisida.

Dalam penyuluhan ini dilakukan uji wilcoxon pengetahuan dan didapatkan skor signifikansi 0,000 $(<0,05)$ artinya terdapat perbedaan signifikan antara skor pre test dan post test. Maka dapat dikatakan bahwa penyuluhan yang dilakukan sudah efektif meningkatkan pengetahuan. Hasil yang bermakna ini menunjukkan bahwa pada kelompok eksperimen terjadi perubahan yang bermakna pada pengetahuan petani bawang merah terhadap penggunaan APD saat pemberian pestisida setelah petani bawang merah mengikuti kegiatan penyuluhan dengan baik.

Sedangkan pada sikap, diketahui hasil analisis skor rata-rata (mean) pre test adalah 12,73 sedangkan skor rata-rata post test adalah 22,40. Artinya terdapat peningkatan sikap setelah dilakukan penyuluhan. Berdasarkan hasil uji wilcoxon didapatkan skor signifikansi $0,000 \quad(<0,05)$ yang artinya terdapat perbedaan signifikan antara skor pre test dan post test. Maka dapat dikatakan bahwa penyuluhan yang dilakukan sudah efektif meningkatkan sikap.

Penyuluhan merupakan hubungan timbal balik antara dua orang individu (penyuluh dan klien) untuk mencapai pengertian tentang diri sendiri dalam hubungan dengan masalah-masalah yang dihadapi pada waktu yang akan datang. Penelitian ini menggunakan metode satu arah dimana materi yang disampaikan oleh pemberi penyuluhan melalui slide 
presentasi dan kertas berisikan materi yang ada pada slide.

Menurut Bloom et al dalam Winkel (2004), pengetahuan mencakup ingatan akan hal-hal yang pernah dipelajari dan disimpan, hal-hal itu dapat meliputi fakta, kaidah dan prinsip serta metode yang diketahui. ${ }^{13}$

Salah satu bentuk daripada upaya intervensi terhadap meningkatnya faktor pengetahuan dan perilaku yang dapat dilakukan yaitu melalui pendekatan pendidikan. Pendekatan pendidikan adalah yang paling tepat sebagai upaya untuk memecahkan masalah kesehatan masyarakat melalui faktor perilaku.

Salah satu upaya dalam bentuk pendidikan kesehatan yang memungkinkan untuk merubah perilaku dan tingkat pengetahuan adalah dengan metode penyuluhan. Penyuluhan merupakan hubungan timbal balik antara dua orang individu (penyuluh dan klien) untuk mencapai pengertian tentang diri sendiri dalam hubungan dengan masalah-masalah yang dihadapi pada waktu yang akan datang.

\section{KESIMPULAN}

Berdasarkan hasil penelitian tentang efektivitas penyuluhan tentang penggunaan APD saat pemberian pestisida kepada Petani Bawang Merah di Desa Tegalglagah melalui uji wilcoxon dengan nilai $\mathrm{p}=0.000$ dan nilai $\mathrm{Z}=-6.771$ dan skor signifikansi $0,000(<0,05)$ yang artinya menyimpulkan bahwa terdapat perbedaan signifikan antara skor pre test dan post test. Ini merupakan bukti bahwa upaya dalam meningkatkan pengetahuan dan sikap akan kesadaran para petani bawang merah melalui penyuluhan telah dilakukan dengan baik serta mudah dipahami. Selain itu, upaya melakukan penyuluhan dilakukan untuk meningkatkan pengetahuan tentang APD dan bahaya pestisida dengan metode pemberian penyuluhan, pemberian materi hardcopy maupun informasi yang menarik dan mudah dipahami seperti membuat spanduk yang berisikan peringatan untuk selalu menggunakan APD selama bekerja dan penyakit yang ditimbulkan bila terpapar pestisida agar para petani bawang merah memiliki peningkatan kesadaran dan sikap waspada dalam bekerja.

\section{Acknowledgement}

Penulis dalam penelitian ini mengucapkan terima kasih kepada Petani Bawang Merah Desa Tegalglagah Kecamatan Bulakamba Kabupaten Brebes Jawa Tengah yang telah mengizinkan serta turut ikut berkontribusi sebagai responden dalam pelaksanaan penelitian ini.

\section{Conflict of Interest}

Peneliti tidak memiliki kepentingan yang dapat mempengaruhi atas pekerjaan penelitian dan hasil penelitian.

\section{Author Contribution}

SH berkontribusi dalam penentuan ide, penyusunan proposal, membuat proposal penelitian, mengoordinasikan tim, menyusun dan mengoreksi laporan akhir. SA berkontribusi dalam mengolah data penelitian, Membuat laporan penelitian analisis dan interpretasi data penelitian.

\section{DAFTAR PUSTAKA}

1. Sularti, Muhlisin A. Tingkat Pengetahuan Bahaya Pestisida Dan Kebiasaan Penggunaan alat pelindung diri Dilihat Dari Munculnya Tanda Gejala Keracunan Pada Kelompok Tani Di Karanganyar. Kesehatan UMM. 2012.

2. Lasmi S, Jannah N. Perilaku Petani Sayuran Dalam Penggunaan Alat Pelindung Diri (Apd) Di Kelurahan Parangbanoa Kecamatan Pallangga Kabupaten Gowa. Sulolipu Media Komun Sivitas Akaddan Masy. 2020.

3. Minaka, I. A. D. A., Sawitri, A. A. S., \& Wirawan, D. N. 2019. Hubungan Penggunaan Pestisida dan Alat Pelindung Diri dengan Keluhan Kesehatan pada Petani Hortikultura di Buleleng, Bali. Public Health and Preventive Medicine Archive 2019, Vol.4, No.1.

4. Mahyuni, EL. Faktor Risiko Dalam Penggunaan Pestisida Terhadap Keluhan Kesehatan Pada Petani di Kecamatan Berastagi Kabupaten Karo. Jurnal Kesmas 2015; 9(1): 79 t89.

5. Budiawan AR, Faktor Risiko Cholinesterase Rendah Pada Petani Bawang Merah. Jurnal KESMAS. KEMAS: 8 (2) (2013) 198-206.

6. Dinaediana D. Hubungan Kenyamanan, Pengetahuan Dan Sikap Petani Dengan Penggunaan Alat Pelindung Diri Pestisida Pada Petani Jeruk. Hum Care J. 2017.

7. Notoatmojo S. Konsep perilaku kesehatan. Promosi kesehatan, Teori dan Apl.2010.

8. Danti A. Pengaruh Pemutaran Media Audio Visual (Video) Terhadap Peningkatan Pengetahuan Tentang Keracunan Pestisida Pada Petani Bawang Merah Brebes. Uns. Semarang;2015.

9. Azwar S. Sikap Manusia: Teoridan Pengukurannya. Sikap Manusia: Teoridan Pengukurannya. 2013

10. Khamidi T. Wiyono S. dkk. Pengetahuan, Sikap Dan Tindakan Petani DI Kabupaten Tegal Dalam Penggunaan Pestisida. Jurnal Bumi. 2010.

11. Supriyanto, Apriliani. dkk. Perilaku Penggunaan Alat Pelindung Diri (APD) Pada Petani Pengguna Pestisida Di Desa Cikole Kecamatan Lembang Kabupaten Bandung Barat.

12. Saputri E, Puteri DA. dkk. Pengaruh Penyuluhan Terhadap Pengetahuan, Sikap Dan Tindakan Petani Jeruk Di Desa Kuok 
Pulau Jambu Terkait Penggunaan Alat Pelindung Diri (APD). Jurnal Imliah Ilmu Kesehatan 2021;1(1).

13. Tatuhey RR, August E, dkk. Pengetahuan, Sikap Dan Perilaku
Petani Terhadap Penggunaan Pestisida Kimia Di Kota Ambon. AGRILAN : Jurnal Agribisnis Kepulauan 2020; 8(1). 